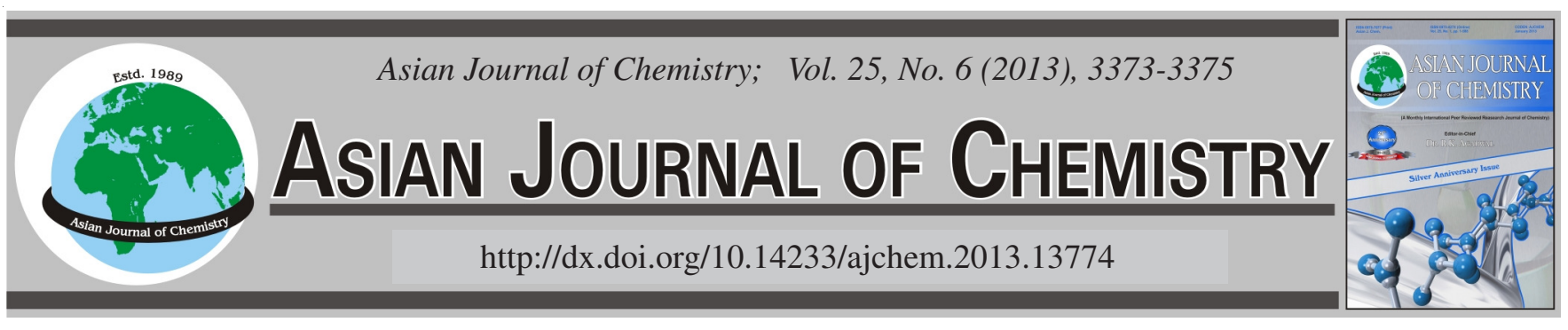

\title{
Synthesis of Spiro Heterobicyclic Rings Using Cellulose Sulfuric Acid Under Solvent Free Conditions
}

\author{
Naser Montazeri ${ }^{*}$, Khalil Pourshamsian, Masoud Bayazi and Soudabeh Kabiri
}

Department of Chemistry, Tonekabon Branch, Islamic Azad University, Tonekabon, Iran

*Corresponding author: Fax: +98 192 4274409; Tel: +98 192 4274415; E-mail: montazer50@toniau.ac.ir, montazer1350@ gmail.com

Cellulose sulfuric acid is found to be a heterogenic recyclable catalyst for the rapid and efficient synthesis spiro heterobicyclic rings via a three component condensation reaction between aldehydes, barbituric acid and urea (or thiourea) under solvent-free conditions. The method offers several advantages, including high yields, short reaction times, simple work-up procedure and reusability of the catalyst. We believe that this applicability of cellulose sulfuric acid with mention advantages makes our method superior over all reported methods to the synthesis of spiro heterobicyclic compounds.

Key Words: Cellulose sulfuric acid, Solvent-free, Spiro heterobicyclic rings, Barbituric acid.

\section{INTRODUCTION}

Multicomponent condensation reactions have recently been discovered to be a powerful method for the synthesis of organic compounds, since the products are formed in a single step and diversity can be achieved by simply varying each component ${ }^{1-3}$.

Spiro heterocyclic derivatives are important class of heterocycles with a wide range of biological and pharmacological activities such as antiviral, antitumor, antihypertensive, hypertensive, narcotic and analgesic $\mathrm{c}^{4-8}$. In addition, spiro heterocyclic units are present in several bioactive natural products $^{9-12}$. 2,4,8,10-tetra aza spiro [5.5] undecane-1,3,5,9-tetraone compounds are one type of spiro heterocycles that generally synthesized from the reaction of aryl aldehydes, barbituric acid and urea (or thiourea) in the presence of different catalysts such as $p$-TSA ${ }^{13}$ and iodine ${ }^{14}$ or without any catalyst and under microwave irradiation ${ }^{15}$. Despite the merits of these methodologies, harsh reaction conditions, long reaction times, toxicity or difficulty in product separation remain concerns. Therefore, the search for the new protocol for the synthesis of 2,4,8,10tetra aza spiro [5.5] undecane-1,3,5,9-tetraone is still being actively pursued. Cellulose is a polymer raw material used for two general purposes. For many centuries it has served mankind as a construction material, mainly in the form of intact wood and textile fibers such as cotton or flax, or in the form of paper and board. On the other hand, cellulose is a versatile starting material for chemical conversions, being used at the production of artifact, cellulose-based thread and films as well as a variety of stable cellulose derivatives used in many areas of industry and domestic life. Cellulose and its derivatives have some unique properties such as biodegradable, inexpensive, extremely inert and environmentally benign, which make them attractive catalysts for organic or inorganic transformations ${ }^{16}$. Recently, cellulose sulfuric acid has emerged as a promising biopolymeric solid support acid catalyst for various acidcatalyze reactions ${ }^{17-22}$. However, there are no reports on the use of cellulose sulfuric acid for one-pot three-component synthesis of tetra aza spiro [5.5] undecane. In continuation of our previous works on the applications of reusable catalysts in the synthesis of heterocyclic compounds ${ }^{23-28}$. We report cellulose sulfuric acid as a highly efficient, reusable, clean and economically valuable catalyst for the one-pot, threecomponent synthesis of 2,4,8,10- tetra aza spiro [5.5] undecane $-1,3,5,9$ tetraone derivatives $(\mathbf{4} \mathbf{a}-\mathbf{h})$ from reaction of barbituric acid (1), aryl aldehydes (2) and urea or thiourea (3) under solvent-free conditions (Scheme-I).

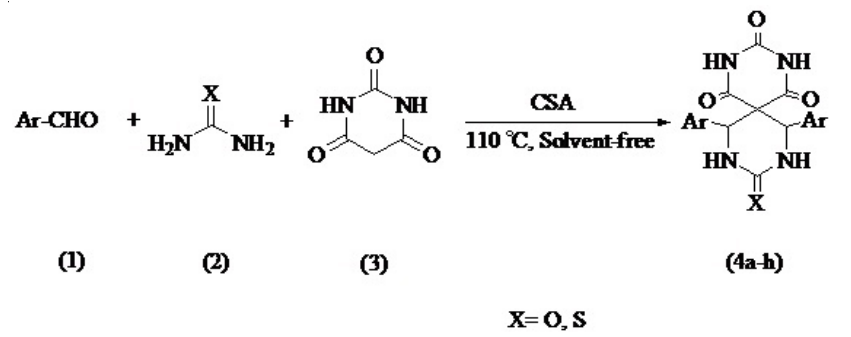

Scheme-I: Synthesis of spiro [2-oxo-4,6-bis(aryl) hexahydropyrimidine-5,5'barbituric acid] 


\section{EXPERIMENTAL}

All chemicals were available commercially and used without additional purification. Melting points were recorded on an electro-thermal type 9100 melting point apparatus. The IR spectra were obtained using 4300 Shimadzu spectrophotometer as $\mathrm{KBr}$ disks. The ${ }^{1} \mathrm{H}$ NMR (400 MHz) spectra were recorded with a Bruker DRX 400 spectrometers.

Preparation of cellulose sulfuric acid: To a magnetically stirred mixture of cellulose $(5 \mathrm{~g})$ and of $n$-hexane $(20 \mathrm{~mL})$, chlorosulfonic acid $(1.00 \mathrm{~g}, 9 \mathrm{mmol})$ was added dropwise at $0{ }^{\circ} \mathrm{C}$ during $2 \mathrm{~h} . \mathrm{HCl}$ gas was removed from the reaction. Vessel immediately the reaction mixture was stirred for $2 \mathrm{~h}$ and filtered. The residue was washed with acetonitrile $(30 \mathrm{~mL})$ and dried at room temperature to afford $5.15 \mathrm{~g}$ of cellulose sulfuric acid as a white powder ${ }^{22}$.

Synthesis of spiro[2-oxo-4,6-bis(aryl)hexahydro pyrimidine-5,5'-barbituric Acids] (4a-h) catalyzed by cellulose sulfuric acid: A mixture of burbituric acid $\mathbf{1}$ (1 mmol), aryl aldehydes 2 ( $2 \mathrm{mmol})$, urea or thiourea 3 (1 mmol ) and cellulose sulfuric acid $(0.05 \mathrm{~g})$ as a catalyst was heated at $110{ }^{\circ} \mathrm{C}$ with stirring for $4 \mathrm{~min}$. After completion of the reaction as indicated by TLC, the resulting solid product was cooled to room temperature. The boiling ethanol was added and the catalyst was filtrated. The filtrate was concentrated to give the solid product that washed with water and recrystallized in the ethanol to give pure products $(\mathbf{4 a - h})$. The structures of the products were confirmed by ${ }^{1} \mathrm{H}$ NMR and IR spectroscopies and comparison with authentic samples prepared by reported methods ${ }^{4,14}$.

Recycling and reusing of the catalyst: At the end of the reaction, the catalyst could be recovered by a simple filtration. The recovered catalyst was washed with chloroform and dried at $60^{\circ} \mathrm{C}$ under vacuum for $5 \mathrm{~h}$. It was reused in another reaction without appreciable reduction in the catalytic activity.

Spiro-(2-oxo-4,6-diphenylhexahydropyrimidine-5,5barbituric acid): $4 a$ m.p. $240-241^{\circ} \mathrm{C}$. IR $\left(\mathrm{KBr}, v_{\max }, \mathrm{cm}^{-1}\right)$ : 3360, $3150(\mathrm{NH}), 1735$ and $1690(\mathrm{CO}) .{ }^{1} \mathrm{H}$ NMR (DMSO- $d_{6}$ $400 \mathrm{MHz}) \delta(\mathrm{ppm}) ; \delta_{\mathrm{H}}, 5.30(\mathrm{~s}, 2 \mathrm{H}, 2 \mathrm{CH}), 7.10-7.50(\mathrm{~m}$, $10 \mathrm{H}$, aromatic), 7.65 (s, 2H, NH), 11.02, $11.36(2 \mathrm{~s}, 2 \mathrm{H}, \mathrm{NH})$. ${ }^{13} \mathrm{C}$ NMR $\left(100 \mathrm{MHz}, \mathrm{DMSO}-d_{6}\right) \delta(\mathrm{ppm}) ; \delta 57.5\left(\mathrm{C}_{\text {spiro }}\right), 62.2$ $(2 \mathrm{CH}), 127.8,129.0,129.5,137.1,150.1,156.1,166.5$ and 170.5 (4CO)

Spiro-(2-oxo-4,6-bis(p-chlorophenylhexahydropyrimidine-5,5-barbituric acid): $4 \mathbf{b} 290-291{ }^{\circ} \mathrm{C}$. IR (KBr, $v_{\max }$, $\left.\mathrm{cm}^{-1}\right)$ : 3205 and $3065(\mathrm{NH}), 1770,1731$ and $1687(\mathrm{C}=\mathrm{O}) .{ }^{1} \mathrm{H}$ NMR (DMSO- $\left.d_{6} 400 \mathrm{MHz}\right) \delta(\mathrm{ppm}) ; \delta 5.25(2 \mathrm{H}, \mathrm{s}, \mathrm{CH}), 7.20$ (4H, d, 4CH), $7.31(2 \mathrm{H}, \mathrm{s}, 2 \mathrm{NH}), 7.44(4 \mathrm{H}, \mathrm{d}, 4 \mathrm{CH}), 11.19-$ $11.56(2 \mathrm{H}, 2 \mathrm{~s}, \mathrm{NH}) .{ }^{13} \mathrm{C}$ NMR (100MHz DMSO- $\left.d_{6}\right) \delta(\mathrm{ppm}) ;$ $\delta 57.7\left(\mathrm{C}_{\text {spiro }}\right), 60.7(2 \mathrm{CH}), 105.7,155.1(\mathrm{Ar}), 159.6,165.3$ (CO).

Spiro(2-thioxo-4,6-bis(p-methyl)hexahydropyrimidine-5.5'-barbituric acid): 4 f m.p. $275-277^{\circ} \mathrm{C}$. IR $\left(\mathrm{cm}^{-1}\right.$, $\mathrm{KBr}):$ 3325-3213 (NH), 1766, 1716, $1685(\mathrm{C}=\mathrm{O}) .{ }^{1} \mathrm{H}$ NMR $\left(\mathrm{DMSO}-d_{6} 400 \mathrm{MHz}\right) \delta(\mathrm{ppm}) ; \delta 2.45\left(6 \mathrm{H}, \mathrm{s}, 2 \mathrm{CH}_{3}\right), 5.36$ $(2 \mathrm{H}, \mathrm{s}, 2 \mathrm{CH}), 7.31(4 \mathrm{H}, \mathrm{d}, 4 \mathrm{CH}), 8.10(4 \mathrm{H}, \mathrm{d}, 2 \mathrm{NH}), 11.23-$ $11.37(2 \mathrm{H}, 2 \mathrm{~s}, \mathrm{NH}){ }^{13} \mathrm{C}$ NMR(100 MHz, DMSO- $\left.d_{6}\right) \delta(\mathrm{ppm})$; $\delta 21.8\left(2 \mathrm{CH}_{3}\right), 56.9(\mathrm{CH}), 57.06\left(\mathrm{C}_{\text {spiro }}\right), 129.3-150.5(\mathrm{Ar})$, $155.4(\mathrm{C}=\mathrm{S})$ 162.2-164.08(CO).

\section{RESULTS AND DISCUSSION}

In the last decade, the development of environmentally green and easily recyclable catalyst for the production of fine chemicals has been an area of growing interest. In this context, cellulose sulfuric acid as a solid acid catalyst, play prominent role in the synthesis of organic heterocyclic compounds. Cellulose sulfuric acid with high reactivity, high stability, low toxicity, easy preparation and recyclability is one of the most attractive catalysts for organic synthesis ${ }^{17-22}$. Prompted by these findings, we decided to investigate the efficiency of cellulose sulfuric acid as a catalyst in the synthesis of 2,4,8,10-tetra aza spiro [5.5] undecane-1,3,5,9-tetraone derivatives under solvent-free conditions. First, we investigated the synthesis of 4a as a model reaction to select suitable reaction condition. The reaction was carried out under solvent-free conditions in various amounts of cellulose sulfuric acid and also in different temperatures (Table-1). The efficiency of the reaction is mainly affected by different amounts of cellulose sulfuric acid and temperature. In the absence of the catalyst at $110^{\circ} \mathrm{C}$ (entry 1 ) or in the presence of the catalyst at room temperature (entry 2) low yield of product was obtained even after $1 \mathrm{~h}$. These observations indicate that both catalyst and temperature are necessary for completing the reaction. Increasing in amount of the catalyst until $0.05 \mathrm{~g}$ and reaction temperature until 110 ${ }^{\circ} \mathrm{C}$, increased the yield of the product $\mathbf{4 a}$, whereas further increase in both catalyst amount and temperature have an inhibitory effect on formation of the product (entries 12-16). The effects of solvents such as acetone, dichloromethane, chloroform, acetonitrile, methanol and ethanol were also studied. According to entries 14-16 the yield of the reaction under solvent-free conditions was greater and the reaction time was generally shorter than the conventional method.

TABLE-1

EFFECT OF CATALYST, TEMPERATURE AND SOLVENT

ON THE SYNTHESIS OF SPIRO [2-OXO-4,6-BIS-(ARYL)

HEXAHYDROPYRIMIDINE-5, 5'-BARBITURIC ACID ] $]^{\mathrm{a}}$ (MODEL REACTION)

\begin{tabular}{cccccc}
\hline Entry & Catalyst $(\mathrm{g})$ & $\mathrm{T}\left({ }^{\circ} \mathrm{C}\right)$ & Solvent & Time $(\min )$ & Yield $(\%)^{\mathrm{b}}$ \\
\hline 1 & None & 110 & None & 60 & 65 \\
2 & 0.05 & r.t. & None & 60 & 67 \\
3 & 0.03 & 90 & None & 10 & 86 \\
4 & 0.03 & 100 & None & 7 & 89 \\
5 & 0.03 & 110 & None & 6 & 91 \\
6 & 0.04 & 90 & None & 7 & 88 \\
7 & 0.04 & 100 & None & 6 & 90 \\
8 & 0.04 & 110 & None & 6 & 92 \\
9 & 0.05 & 90 & None & 5 & 89 \\
10 & 0.05 & 100 & None & 5 & 91 \\
11 & 0.06 & 110 & None & 4 & 95 \\
12 & 0.06 & 100 & None & 6 & 94 \\
13 & 0.05 & 110 & None & 6 & 95 \\
14 & 0.05 & Reflux & EtOH $^{2}$ & 60 & 54 \\
15 & 0.05 & Reflux & $\mathrm{CH}_{2} \mathrm{Cl}_{2}$ & 40 & 64 \\
16 & 0.05 & Reflux & $\mathrm{CHCl}_{3}$ & 45 & 70 \\
\hline
\end{tabular}

${ }^{\mathrm{a}} 1 \mathrm{mmol}$ barbituric acid, $2 \mathrm{mmol}$ benzaldehyde and $1 \mathrm{mmol}$ urea under different conditions. ${ }^{\text {b }}$ Isolated yields

Based on the above results, this process was extended to variety of aryl aldehydes and urea or thiourea in the optimized system. The results are summarized in Table-2. In all cases, 
TABLE-2

CSA CATALYZED SYNTHESIS OF SPIRO [2-OXO-4,6-BIS-(ARYL) HEXAHYDROPYRIMIDINE-5,5'-BARBITURIC ACID ] (MODEL REACTION) ${ }^{\mathrm{a}}$

\begin{tabular}{|c|c|c|c|c|c|c|c|}
\hline \multirow{2}{*}{ Entry } & \multirow{2}{*}{$\mathrm{Ar}$} & \multirow{2}{*}{$\mathrm{X}$} & \multirow{2}{*}{ Product ${ }^{b}$} & \multirow{2}{*}{ Time (min) } & \multirow{2}{*}{ Yield $^{\mathrm{c}}(\%)$} & \multicolumn{2}{|c|}{ m.p. $\left({ }^{\circ} \mathrm{C}\right)$} \\
\hline & & & & & & Found & Reported \\
\hline 1 & $\mathrm{C}_{6} \mathrm{H}_{5}$ & $\mathrm{O}$ & $4 a$ & 4 & 95 & $240-241$ & $240-241[14]$ \\
\hline 2 & 4- $\mathrm{ClC}_{6} \mathrm{H}_{4}$ & $\mathrm{O}$ & $4 b$ & 7 & 93 & $290-291$ & 289-291[14] \\
\hline 3 & $3-\mathrm{NO}_{2} \mathrm{C}_{6} \mathrm{H}_{4}$ & $\mathrm{O}$ & $4 c$ & 5 & 94 & $221-223$ & $220-222[4]$ \\
\hline 4 & 4- $\mathrm{MeC}_{6} \mathrm{H}_{4}$ & $\mathrm{O}$ & $4 d$ & 6 & 94 & $243-245$ & $246-248[14]$ \\
\hline 5 & $3-\mathrm{CH}_{3} \mathrm{OC}_{6} \mathrm{H}_{4}$ & $\mathrm{O}$ & $4 e$ & 6 & 92 & $237-239$ & $238-239[4]$ \\
\hline 6 & 4- $\mathrm{CH}_{3} \mathrm{C}_{6} \mathrm{H}_{4}$ & $\mathrm{~S}$ & $4 f$ & 6 & 87 & $275-277$ & - \\
\hline 7 & $3-\mathrm{ClC}_{6} \mathrm{H}_{4}$ & $\mathrm{O}$ & $4 g$ & 7 & 89 & $250-251$ & $252-253[4]$ \\
\hline 8 & $\mathrm{C}_{6} \mathrm{H}_{5}$ & $\mathrm{~S}$ & $4 h$ & 5 & 90 & $246-244$ & $247[14]-245$ \\
\hline
\end{tabular}

${ }^{a}$ Reaction condition: barbituric acid $(1 \mathrm{mmol})$, aromatic aldehyde $(2 \mathrm{mmol})$, urea or thiourea $(1 \mathrm{mmol})$ and $\mathrm{CSA}(0.05 \mathrm{~g})$ at $110{ }^{\circ} \mathrm{C}$ under solventfree conditions. ${ }^{\mathrm{b}} \mathrm{All}$ products were characterized by use of IR and ${ }^{1} \mathrm{H}$ NMR spectral data and comparision their melting points with those of outhentic samples. 'Isolated yields based on barbituric acid their melting points with those of authentic samples

reactions reacted successfully and gave the expected products in excellent yields. The type of aldehyde and urea or thiourea had no significant effect on the reaction.

Reusability of the catalyst was also investigated for this purpose, the reaction of barbitric acid, benzaldehyde urea and cellulose sulfuric acid was again studied under the optimized conditions. After completion of the reaction, the catalyst was recovered according to the procedure mentioned in experimental section and reused for a similar reaction. The catalyst could be used at least three times with only slight reduction in the catalytic activity (94\% for 1st use; $87 \%$ for 2 nd use; $84 \%$ for 3rd use).

\section{Conclusion}

In conclusion, cellulose sulfuric acid has shown to be an excellent catalyst for one pot three-component synthesis of spiro heterocyle derivatives under solvent-free conditions. The availability and stability of the catalyst, the simple work-up procedure, excellent yields and recyclability of the catalyst, make this method a valid contribution to the existing methodologies.

\section{ACKNOWLEDGEMENTS}

The authors gratefully acknowledged the financial support of this research by Islamic Azad University, Tonekabon Branch.

\section{REFERENCES}

1. R.V.A. Orru and M. deGreef, Synthesis, 1471 (2003).

2. L.F. Tietze and A. Modi, Med. Res. Rev., 20, 304 (2000).

3. I. Ugi, A. Domling and B. Werner, J. Heterocyc. Chem., 37, 647 (2000).

4. J.L. Mokrosz, M.H. Psluchowska, E. Szneler and B. Drozdz, Arch. Chem., 322, 231 (1989).

5. A.C. Cope, P. Kovacic and M. Burg, J. Am. Chem. Soc., 71, 3656 (1949).
6. M.I. Al-Ashmawi, K.M. Ghoneim and M. Khalifa, Pharmaze, 35, 591 (1980).

7. W.O. Foye, Principle of Medicinal Chemistry (Lea and Febiger, London) 159 (1989).

8. L.S. Goodman and A. Gilman, The Pharmacological Basis of Therapeutics (McGraw-Hill, New Delhi) p. 358 (1991).

9. H. Arimoto, I. Hayakawa, M. Kuramoto and D. Uemure, Tetrahedron Lett., 36, 861 (1998).

10. T. Chou, M. Kuramoto, Y. Otani, M. Shkano, K. Yazawa and D. Uemere, Tetrahedron Lett., 37, 387 (1996).

11. T. Tokuyama, K. Uenoyama, G. Brown, J.W. Daly and B. Witkop, Helv. Chim. Acta, 57, 2597 (1974).

12. M. Kuramoto, C. Tong, K. Yamada, T. Chiba, Y. Hayacshi and D. Uemura, Tetrahedron Lett., 37, 3867 (1996).

13. K.F. Shelke, S.B. Spakal, G.K. Kakade, B.B. Shingate and M.S. Shingare, Green Chem. Lett. Rev., 3, 27 (2010).

14. D. Parajapati, D. Bhaugan, M. Gohain and W. Hu, Mol. Divers, 15, 257 (2011).

15. A. Shaabani and A. Bazgir, Tetrahed. Lett., 45, 2575 (2004).

16. D. Klemm, B. Heublein, H.P. Fink and A. Bohn, Angew. Chem. Int. Ed., 44, 3358 (2005).

17. P.N. Reddy, Y.T. Reddy, M.N. Reddy, B. Rajitha and P.A. Crooks, Synth. Commun., 39, 1257 (2009).

18. A. Shaabani, A. Ranmati and Z. Badri, Catal. Comm., 9, 13 (2008).

19. S.A. Sadaphal, S.S. Sonar, M.N. Ware and M.S. Shingare, Green Chem. Lett. Rev., 1, 191 (2008).

20. A. Shaabani, A.H. Rezayan, M. Behnam and M. Heidary, C.R. Chimie, 12, 1249 (2009).

21. B.S. Kuarm, J.V. Madhav, B. Rajitha, Y.T. Reddy, P.N. Reddy and P.A. Crooks, Syn. Commun., 41, 662 (2011).

22. J.V. Madhav, Y.T. Reddy, P.N. Reddy, M.N. Reddy, S. Kuarm, P.A. Crooks and B. Rajitha, J. Mol. Catal. A, 304, 85 (2009).

23. N. Montazeri and K, Rad-Moghadam, Chin. Chem. Lett., 19, 1143 (2008).

24. N. Montazeri, S. Khaksar, A. Nazari, S.S. Alavi, S.M. Vahdat and M. Tajbakhsh, J. Fluorine Chem., 132, 450 (2011).

25. N. Montazeri and K. Rad-Moghadam, Phosphona, Sulfur, Silicon Rel. Elem., 179, 2533 (2004).

26. N. Montazeri, Asian J. Chem., 22, 7432 (2010).

27. N. Montazeri and K. Rad-Moghadam, Asian J. Chem., 18, 1557 (2006).

28. F. Hatamjafari, N. Montazeri and K. Pourshamsian, Asian J. Chem., 23, 3287 (2011). 